\title{
Statins induce apoptosis and inhibit proliferation in cholangiocarcinoma cells
}

\author{
MICHIHIRO KAMIGAKI, TAMITO SASAKI, MASAHIRO SERIKAWA, MOTOKI INOUE, KENSO KOBAYASHI, \\ HIROSHI ITSUKI, TOMOYUKI MINAMI, MASANOBU YUKUTAKE, AKIHITO OKAZAKI, \\ TAKASHI ISHIGAKI, YASUTAKA ISHII, KEIICHI KOSAKA and KAZUAKI CHAYAMA
}

Department of Medicine and Molecular Science, Division of Frontier Medical Science, Programs for Biochemical Research, Graduate School of Biochemical Sciences, Hiroshima University, 1-2-3 Kasumi, Minami-ku, Hiroshima 734-8551, Japan

Received March 30, 2011; Accepted May 13, 2011

DOI: $10.3892 /$ ijo.2011.1087

\begin{abstract}
Given the poor prognosis for cholangiocarcinoma, new and effective treatments are urgently needed. HMG-CoA reductase inhibitors (statins) reportedly exert anticancer effects in a variety of diseases, but there have been no reports of these effects in cholangiocarcinoma. In this study, we investigated the utility of statins for cholangiocarcinoma treatment. Proliferation suppression by pitavastatin and atorvastatin was investigated in the human cholangiocarcinoma cell lines HuCCT1 and YSCCC while changes in the cell cycle and intracellular signals were examined by FACS and Western blotting, respectively. Additive proliferation suppression by statins and pre-existing anticancer drugs was also investigated. HuCCT1 and YSCCC cell proliferation was dramatically suppressed by incubation with statins for $72 \mathrm{~h}$ or longer. Cell cycle analysis revealed a reduction in the $\mathrm{G} 2 \mathrm{M}$ fraction and an increase in the sub-G1 fraction in statin-treated cells, while Western blotting showed increased levels of cleaved caspase-3 and a reduction in p-ERK. Furthermore, statins in combination with gemcitabine, cisplatin and 5-FU showed additive proliferation suppression. In this study, treatment of human cholangiocarcinoma cells with statins induced apoptosis via suppression of the classical MAPK pathway. Together, these results suggest that statins may be a new cholangiocarcinoma treatment option that could potentially enhance the anticancer effect of pre-existing anticancer drugs.
\end{abstract}

\section{Introduction}

Among gastroenterological cancers, cholangiocarcinoma is difficult to diagnose and only a small percentage of cases can

Correspondence to: Dr Michihiro Kamigaki, Department of Medicine and Molecular Science, Division of Frontier Medical Science, Programs for Biochemical Research, Graduate School of Biochemical Sciences, Hiroshima University, 1-2-3 Kasumi, Minami-ku, Hiroshima 734-8551, Japan

E-mail: m-kamigaki@hiroshima-u.ac.jp

Key words: statins, ERK, caspase-3, cholangiocarcinoma be curatively resected surgically. The prognosis for cholangiocarcinoma is markedly poor with a five-year survival rate of $<5 \%(1,2)$.

According to the study by Valle et al, gemcitabine plus cisplatin treatment was recently recommended as the primary treatment for surgically unresectable advanced or recurrent cholangiocarcinoma, but the median survival time with this treatment was still only 11.7 months (3). Therefore, improved treatment protocols for cholangiocarcinoma are urgently needed. HMG-CoA reductase inhibitors (statins) are used to treat hypercholesterolemia by inhibiting synthesis of serum lipids such as cholesterol and triglyceride $(4,5)$, which can prevent cardiovascular events by protecting the heart and blood vessels (6-9).

A number of recent reports demonstrated that statins inhibit not only cancer growth but also neovascularization and metastasis (10-12). The in vitro effects of statins on cancer, cell cycle regulation (13-15) and apoptosis induction (16-19) have been shown and cancer cell proliferation suppression has been confirmed (10-12). Statins also inhibit growth of cancer in vivo and reduce metastasis at clinical doses $(20,21)$.

Moreover, clinical trials in humans and epidemiological studies demonstrated that the long-term use of statins reduces the onset and progression of colorectal, prostatic, pancreatic and breast cancers (22-25). However, to date, there are no reports as to whether statins have beneficial effects for cholangiocarcinoma. In this study, we aimed to clarify statin-induced differentiation and growth suppression in cholangiocarcinoma cells, the underlying molecular and biological mechanism of this effect, and explore the possibility of statins as a new treatment option for cholangiocarcinoma.

\section{Materials and methods}

Materials. Human extrahepatic cholangiocarcinoma HuCCT1 and human intrahepatic cholangiocarcinoma YSCCC cells were purchased from the Riken Cell Bank (Japan). Pitavastatin was provided by Kowa (Japan). Atorvastatin was supplied by Astellas (Japan). Gemcitabine and cisplatin were purchased from Toronto Research Chemicals Inc. (Canada) and Calbiochem (Germany), respectively, while 5-FU was purchased from Wako (Japan). The final concentration of dimethyl sulfoxide 
(DMSO) (Sigma-Aldrich, St. Louis, MO) added to the cell solution was $<0.2 \%$ and produced no effects.

Cell culture. Human cholangiocarcinoma HuCCT1 and YSCCC cells were used in all experiments and were cultured in RPMI1640 (Gibco BRL ${ }^{\circledR}$ ) supplemented with 10\% fetal bovine serum (FBS) and $1 \%$ penicillin/streptomycin in $95 \%$ air and $5 \% \mathrm{CO}_{2}$ at $37^{\circ} \mathrm{C}$. Microscopic cell images were recorded by phase-contrast imaging with a BIOREVO BZ-9000 fluorescence microscope (Keyence).

Cell proliferation assay. Cells in the exponential growth phase were seeded $\left(5-10 \times 10^{3}\right.$ cells) in 96-well micro-titer plates and cultured for $24 \mathrm{~h}$. After confirmation of cell adherence, atorvastatin and pitavastatin were added to each well at final concentrations of $0-20 \mu \mathrm{M}$ and the cells cultured for an additional 24-96 h. Cell proliferation was measured with the Cell Counting Kit-8 (Dojindo, Japan) according to the manufacturer's protocol. Briefly, $10 \mu \mathrm{l}$ of WST-8 mixture (final concentration, $0.5 \mathrm{mM}$ ) and 1-methoxy PMS (final concentration, $20 \mu \mathrm{M}$ ) was added to each well and the plate incubated in a $\mathrm{CO}_{2}$ incubator for $4 \mathrm{~h}$. To examine cell proliferative activity, absorbance at $450 \mathrm{~nm}$ wavelength with a reference at $620 \mathrm{~nm}$ was measured with a 680 micro-plate reader (Bio-Rad, USA).

To determine the additive growth inhibitory effect of anticancer drugs and statins, $1 \times 10^{4}$ exponential growth cells were seeded in a 96-well micro-titer plate. After confirmation of stable adherence, the cells were cultured for an additional $48 \mathrm{~h}$ whereupon the culture medium was replaced with medium containing either statins (final concentration $20 \mu \mathrm{M}$ ) or DMSO (control group). Gemcitabine, cisplatin and 5-FU were added at a final concentration of $1-40 \mu \mathrm{M}$ and the cells incubated for $48 \mathrm{~h}$. Cell proliferative activity was measured with the Cell Counting Kit-8.

Cell cycle analysis. Cells reacted with statins at varying concentrations were treated with trypsin, detached from the plate, and centrifuged at 1,000 rpm for $5 \mathrm{~min}$ at room temperature. After aspirating the medium, cells were resuspended in cold PBS. The cells were then fixed in ethanol while vortexing and stored at $-20^{\circ} \mathrm{C}$ in $70 \%$ ethanol.

For analysis, cells were centrifuged at $1,000 \mathrm{rpm}$ for $5 \mathrm{~min}$ at room temperature and centrifuged again to remove the ethanol. Cells were rinsed twice with PBS and stained for 30 min with $1 \mu \mathrm{g} / \mathrm{ml}$ propidium iodide (Sigma) in PBS after the addition of RNase A (Sigma). The cell cycle was analyzed with FACSCalibur (Becton-Dickinson, San Jose, CA).

Western blotting. Cells were rinsed twice with ice-cold PBS and treated with $100 \mu 1$ sample buffer (SDS $\beta$-ME) on ice for $30 \mathrm{~min}$. The whole cell lysate was centrifuged at $12,500 \mathrm{rpm}$ for $15 \mathrm{~min}$ at $4^{\circ} \mathrm{C}$. Protein lysates $(20 \mu \mathrm{l})$ were electrophoresed on a $12 \%$ SDS gel.

Proteins were transferred to a PVDF membrane (Bio-Rad) and the membrane was blocked for $1 \mathrm{~h}$ with blocking solution (5\% non-fat dry milk in TBS- $0.5 \%$ Tween-20). The membrane was then reacted overnight at $4^{\circ} \mathrm{C}$ with primary antibodies diluted 1:1,000. The following primary antibodies were used: ERK 1/2 rabbit polyclonal antibody (no. 9102, Cell Signaling
Technology), phospho-ERK1/2 (Thr202/Tyr204) rabbit polyclonal antibody (no. 9101, Cell Signaling Technology), cleaved caspase-3 (Asp175) rabbit polyclonal antibody (no. 9664, Cell Signaling Technology), and actin goat polyclonal antibody (sc-1616, Santa Cruz Biotechnology).

A peroxidase-labeled secondary antibody was then added to the membrane reacted with a primary antibody. After rinsing, the membrane was treated with chemiluminescence solution for $5 \mathrm{~min}$. Specific bands were detected on X-ray film following appropriate exposure to light in the dark room or with VersaDoc 5000MP (Bio-Rad) for image processing. We evaluated the resulting bands by densitometric measurement with Image J (NIH, USA). Actin and ERK were used as internal controls for cleaved caspase-3 and p-ERK, respectively.

Statistical analysis. All experiments were carried out in triplicate. All experiments were repeated three times and expressed graphically as the average \pm SD. Student's t-test was used for statistical analysis, and $\mathrm{p}<0.05$ was considered statistically significant. Statistica software (StatSoft, USA) was used for analysis.

\section{Results}

Growth suppression in cholangiocarcinoma cells by statins. We first examined growth suppression of HuCCT1 and YSCCC cells by pitavastatin and atorvastatin using a cell proliferation assay. The proliferative activity of viable cells depending on the drug concentration and exposure time was evaluated by absorbance measurements. Compared with the control, cell proliferative activity was significantly suppressed by 20.5 $(\mathrm{p}=0.00005)$ and $41.0 \%(\mathrm{p}=0.00001)$ in YSCCC cells and $18.4(\mathrm{p}=0.00044)$ and $46.5 \%(\mathrm{p}=0.00014)$ in HuCCT1 cells following a 96-h exposure to pitavastatin at 10 and $20 \mu \mathrm{M}$, respectively (Fig. 1). Upon a 96-h exposure to atorvastatin at 10 and $20 \mu \mathrm{M}$, respectively, cell proliferative activity was significantly suppressed relative to control cells by $14.2(\mathrm{p}=0.00369)$ and $28.6 \%(\mathrm{p}=0.00008)$ in YSCCC cells and $11.3(\mathrm{p}=0.00256)$ and $26.4 \%$ ( $\mathrm{p}=0.00015)$ in HuCCT1 cells (Fig. 1).

We examined and recorded time-course morphological changes in cholangiocarcinoma cells induced by pitavastatin and atorvastatin using microscopy with phase-contrast imaging. For YSCCC cells, statin exposure shortened the cell diameter, reduced pseudopod formation, and decreased the cell number per view. These changes were more marked for 20 vs. $10 \mu \mathrm{M}$ statins and for 96 vs. 48-h exposure (Fig. 2). HuCCT1 cells underwent similar morphological changes (data not shown).

Apoptosis induction in cholangiocarcinoma cells by statins. We examined cell morphological changes by staining and FACS. Cells were stained with propidium iodide and subjected to cell cycle analysis. Compared with the control, statin-treated cells showed a reduction in side scatter (SSC) and forward scatter (FSC) and a tendency toward reduced cell diameter and density (Fig. 3). Compared with DMSO-treated controls, 96-h exposure to $20 \mu \mathrm{M}$ pitavastatin and atorvastatin reduced the G2M fraction from 19.01 to 13.72 and $14.21 \%$, respectively, and increased the subG1 fraction from 2.47 to 14.4 and $11.36 \%$, respectively, which indicated that apoptosis was induced (Fig. 3 and Table I). These changes were more marked at 96 than at 
(a)

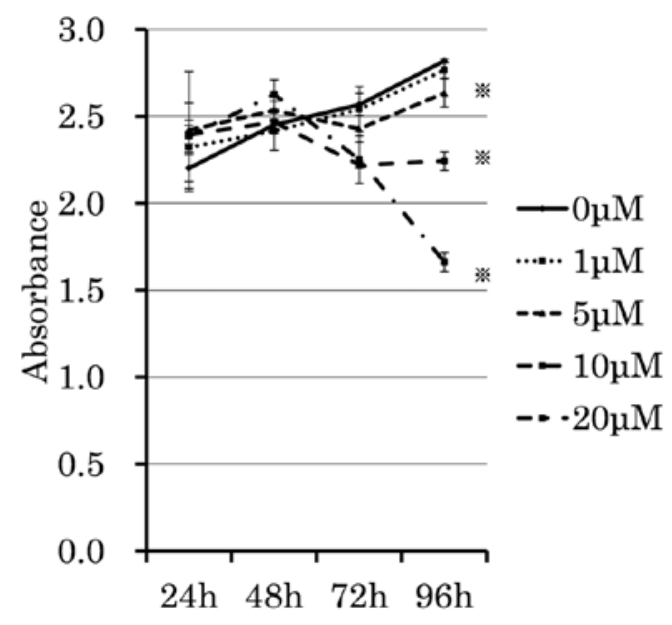

(c)

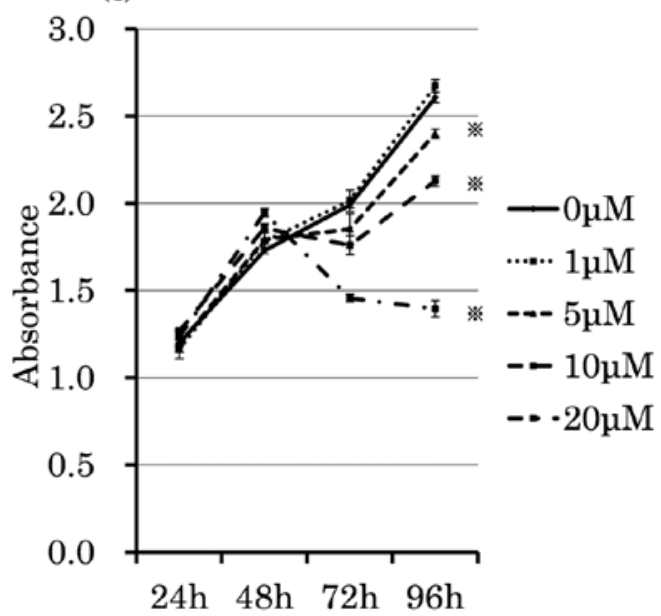

(b)

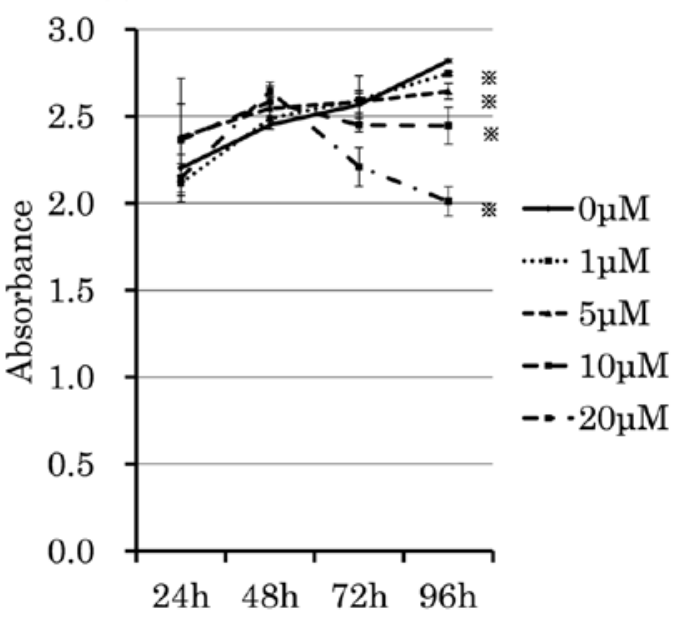

(d)

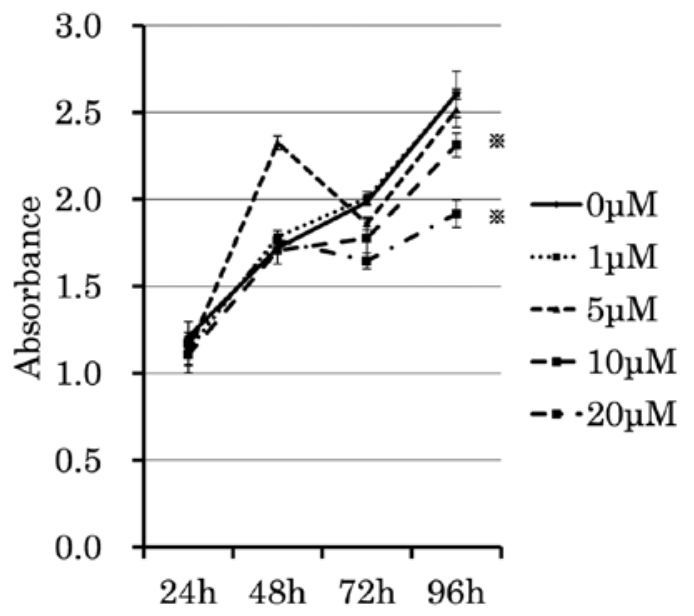

Figure 1. Proliferation suppression in cholangiocarcinoma cells by statins. Proliferation suppression in YSCCC (a and b) and HuCCT1 cells (c and d) by pitavastatin ( $\mathrm{a}$ and $\mathrm{c}$ ) and atorvastatin ( $\mathrm{b}$ and $\mathrm{d}$ ). All data represent absorbance at $450 \mathrm{~nm}$ as measured with a micro-plate reader. The average $\pm \mathrm{SD}$ ( $\mathrm{n}=3$ ) is shown and asterisks indicate a significant difference compared to the control (t-test, $\mathrm{p}<0.05)$.

Table I. Changes in the cell cycle by exposure to statin in cholangiocarcinoma YSCCC cells.

\begin{tabular}{|c|c|c|c|c|c|c|}
\hline \multirow[b]{2}{*}{$\begin{array}{l}\text { Cell cycle } \\
\text { phase }\end{array}$} & \multicolumn{3}{|c|}{$48 \mathrm{~h}$} & \multicolumn{3}{|c|}{$96 \mathrm{~h}$} \\
\hline & Control & $\begin{array}{l}\text { Pitavastatin } \\
\quad(20 \mu \mathrm{M})\end{array}$ & $\begin{array}{l}\text { Atorvastatin } \\
\quad(20 \mu \mathrm{M})\end{array}$ & Control & $\begin{array}{l}\text { Pitavastatin } \\
\quad(20 \mu \mathrm{M})\end{array}$ & $\begin{array}{l}\text { Atorvastatin } \\
\quad(20 \mu \mathrm{M})\end{array}$ \\
\hline G1 (\%) & 64.76 & 72.55 & 70.96 & 66.67 & 48.59 & 49.13 \\
\hline $\mathrm{S}(\%)$ & 14.9 & 10.29 & 8.22 & 12.04 & 14.65 & 24.92 \\
\hline $\mathrm{G} 2 \mathrm{M}(\%)$ & 19.79 & 14.26 & 23.46 & 19.01 & 13.72 & 14.21 \\
\hline Sub G1 (\%) & 2.24 & 5.07 & 1.24 & 2.47 & 14.4 & 11.36 \\
\hline
\end{tabular}

$48 \mathrm{~h}$ and at 20 than $10 \mu \mathrm{M}$ statin. No changes were observed for control cells exposed to DMSO at the same concentration (Fig. 3). Similar phenomena were observed for HuCCT1 cells. (Data for $10 \mu \mathrm{M}$ in HuCCT1 cells are not shown).

Changes in proteins involved in survival signals (caspase-3 and ERK) in cholangiocarcinoma cells. To investigate the effect of statins on caspase-3 and ERK, we collected cells after exposure to statins for different periods and examined the changes in intracellular signaling proteins by Western blotting.

In YSCCC cells, exposure to $20 \mu \mathrm{M}$ pitavastatin timedependently elevated cleaved caspase-3 levels (cleaved caspase-3/actin) to 120.0 and $281.2 \% 48$ and $96 \mathrm{~h}$ after addition, respectively. Exposure to atorvastatin temporarily decreased 

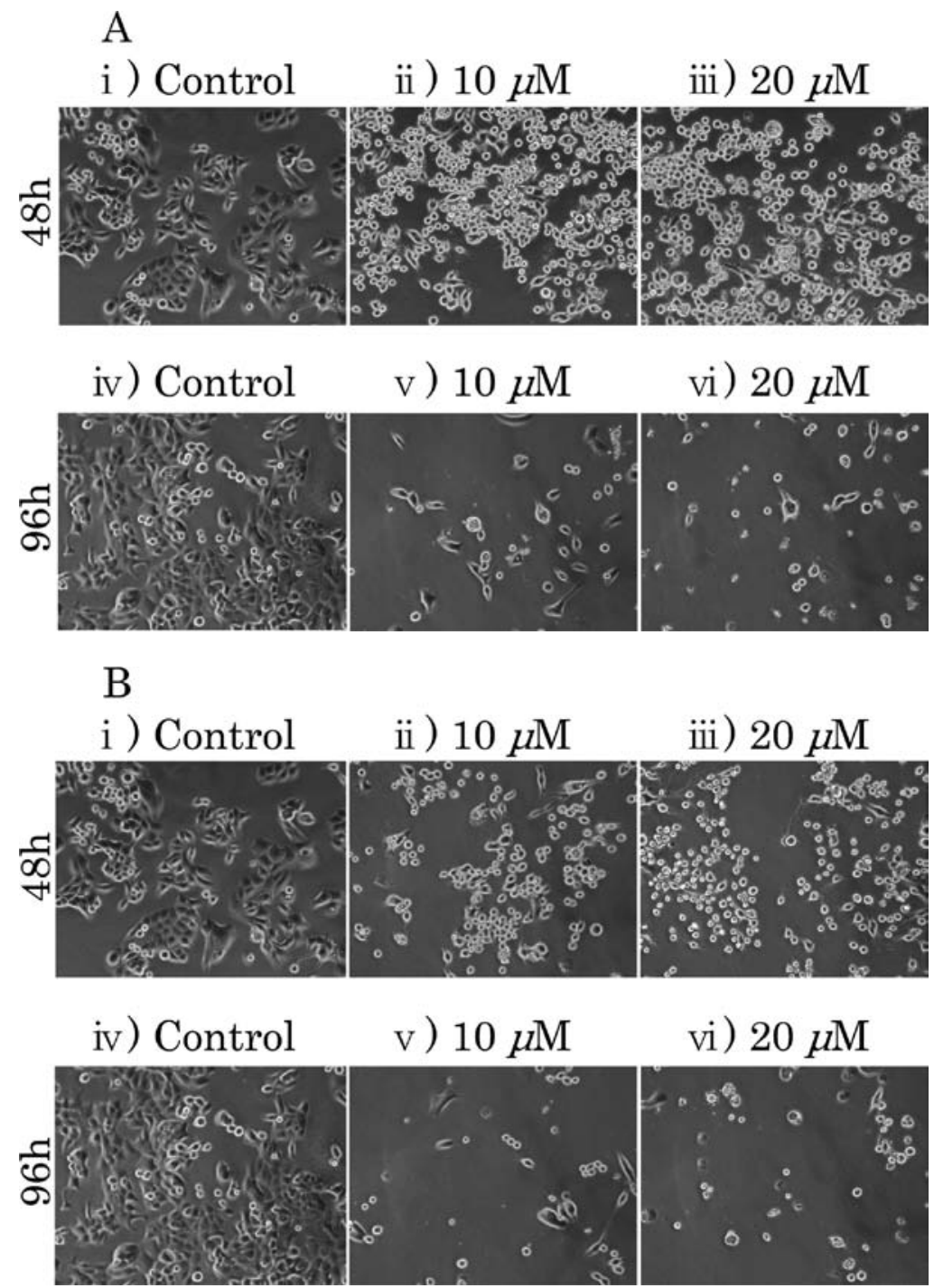

Figure 2. Morphological changes in cholangiocarcinoma cells induced by statins. Phase-contrast microscopy imaging revealed a tendency towards smaller cell diameter and fewer cells per view compared with control cells following statin treatment. (A) Suppression of YSCCC cell proliferation by pitavastatin: (i) DMSO, $48 \mathrm{~h}$; (ii) pitavastatin, $10 \mu \mathrm{M}, 48 \mathrm{~h}$; (iii) pitavastatin, $20 \mu \mathrm{M}, 48 \mathrm{~h}$; (iv) DMSO, $96 \mathrm{~h}$; (v) pitavastatin, $10 \mu \mathrm{M}, 96 \mathrm{~h}$; and (vi) pitavastatin, $20 \mu \mathrm{M}, 96 \mathrm{~h}$. (B) Suppression of YSCCC cell proliferation by atorvastatin: (i) DMSO, $48 \mathrm{~h}$; (ii) atorvastatin, $10 \mu \mathrm{M}, 48 \mathrm{~h}$; (iii) atorvastatin, $20 \mu \mathrm{M}, 48 \mathrm{~h}$; (iv) DMSO, $96 \mathrm{~h}$; (v) atorvastatin, $10 \mu \mathrm{M}, 96 \mathrm{~h}$; and (vi) atorvastatin, $20 \mu \mathrm{M}, 96 \mathrm{~h}$.

caspase-3 levels to $69.9 \% 48 \mathrm{~h}$ later, but they were then elevated $159.7 \%$ after $96 \mathrm{~h}$ (Fig. 4A).

Compared with the control, exposure to $20 \mu \mathrm{M}$ pitavastatin time-dependently reduced phosphorylated ERK protein levels (p-ERK/ERK) to 91.5 and $31.0 \%$ at 48 and $96 \mathrm{~h}$, respectively. Exposure to atorvastatin barely changed these levels $48 \mathrm{~h}$ after addition (100.7\%), but phospho-ERK was reduced to $46.4 \%$ by 96 h (Fig. 4B).

Enhanced effect of anticancer drugs by statins in cholangiocarcinoma cells. We used a cell proliferation assay to compare the proliferation suppressive effect in cholangiocarcinoma cells of anticancer drugs used either alone or in combination with statins. Proliferation suppression was more marked in cells pretreated with statins for $48 \mathrm{~h}$ prior to anticancer drug treatment compared to cells exposed to an anticancer drug alone. After exposure to pitavastatin $(20 \mu \mathrm{M})$ for $48 \mathrm{~h}$, gemcitabine, cisplatin and 5-FU were added and the YSCCC cells were cultured for another $48 \mathrm{~h}$. Compared with control cells exposed to these anticancer drugs $(40 \mu \mathrm{M})$ alone, cell proliferative activity was significantly attenuated to $72.7(\mathrm{p}=0.00051), 36.6$ $(\mathrm{p}=0.00002)$ and $62.2 \%(\mathrm{p}=0.00235)$, respectively (Fig. 5A).

Similarly, after exposure to pitavastatin $(20 \mu \mathrm{M})$ for $48 \mathrm{~h}$, gemcitabine, cisplatin and 5-FU were added to HuCCT1 cells and cultured for another $48 \mathrm{~h}$. Compared with control cells exposed to these anticancer drugs $(40 \mu \mathrm{M})$ alone, cell proliferative activity was significantly attenuated to $81.1(\mathrm{p}=0.00047)$, $85.9(p=0.00314)$ and $81.6 \%(p=0.00432)$, respectively (Fig. 5B) (data not shown for atorvastatin).

\section{Discussion}

Chronic bile stasis and ensuing chronic inflammation are reported to cause genome injury by releasing a variety of cytokines and growth factors in situ, such as IL-6, AKT, EGF and MAPK, which results in persistent cell differentiation 
(A)

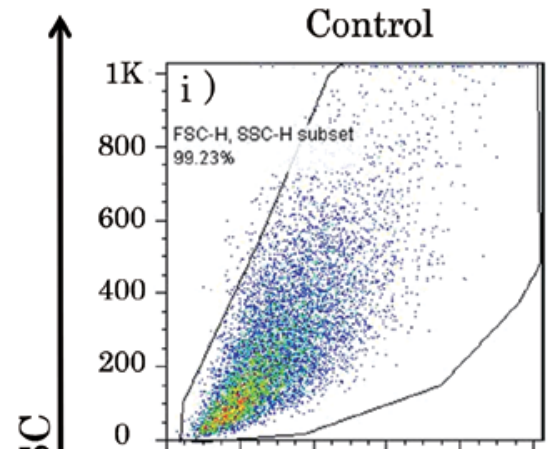

Pitavastatin
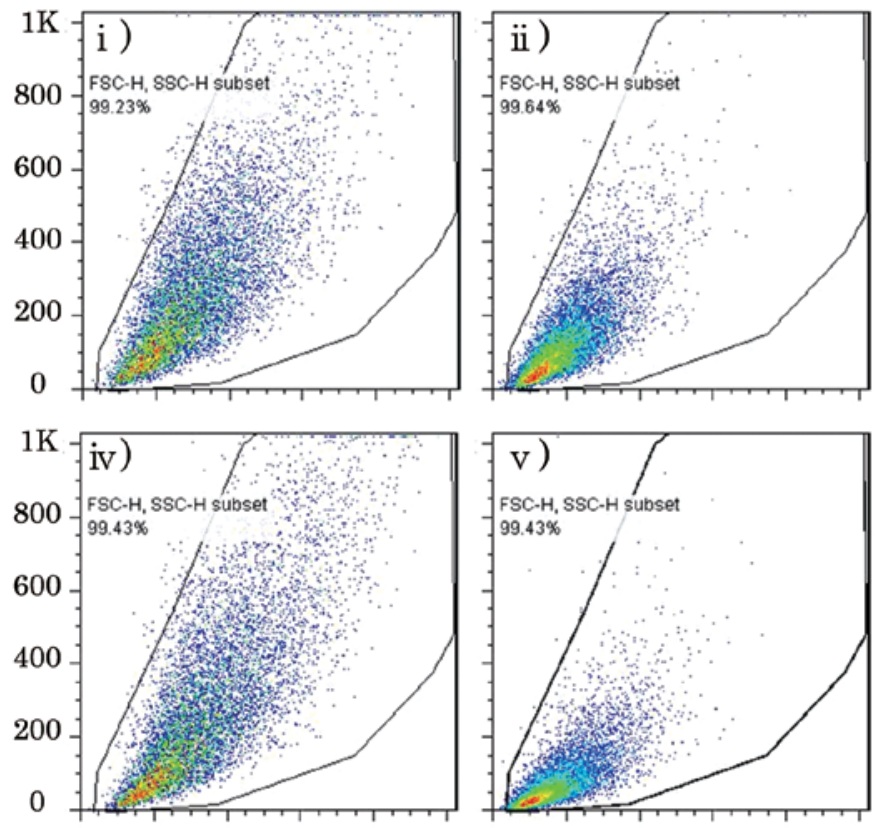

$\begin{array}{llllllllllllllllll}0 & 200 & 400 & 600 & 800 & 1 \mathrm{~K} & 0 & 200 & 400 & 600 & 800 & 1 \mathrm{~K} & 0 & 200 & 400 & 600 & 800 & 1 \mathrm{~K}\end{array}$
Atorvastatin

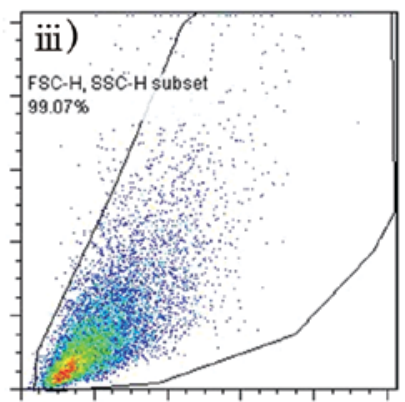

$48 \mathrm{~h}$

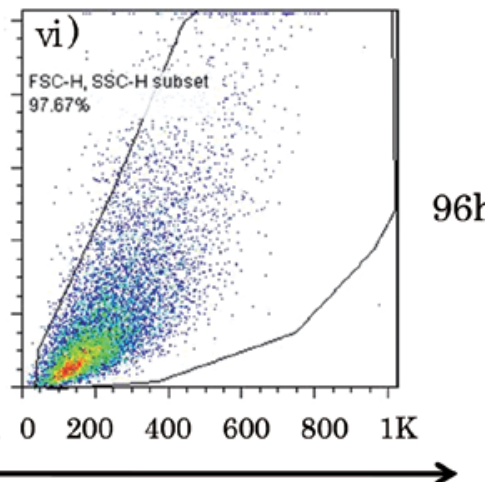

$96 \mathrm{~h}$

FSC

(B)

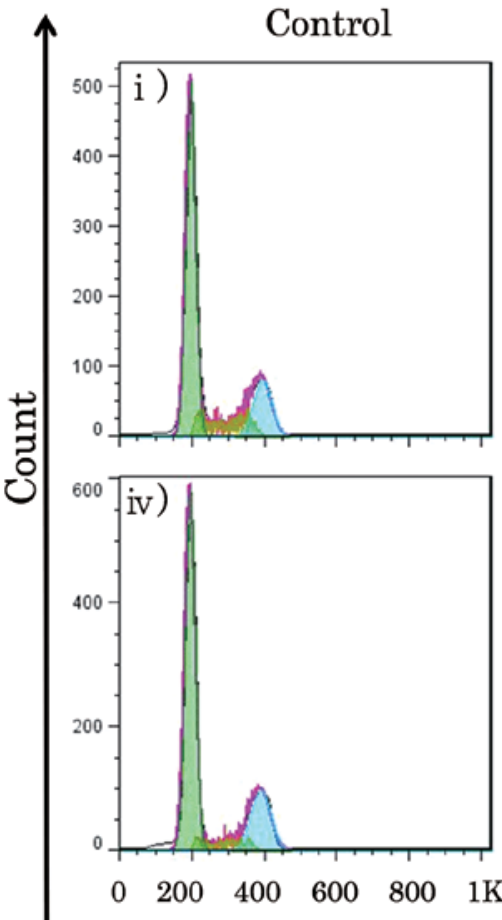

Pitavastatin

Atorvastatin
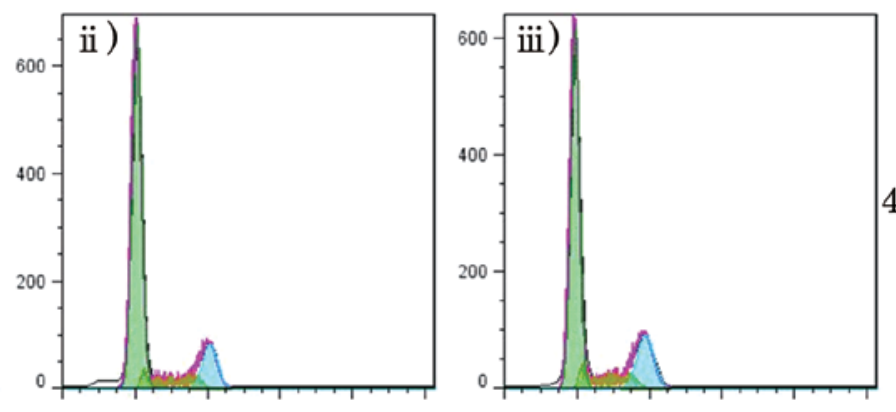

$48 \mathrm{~h}$
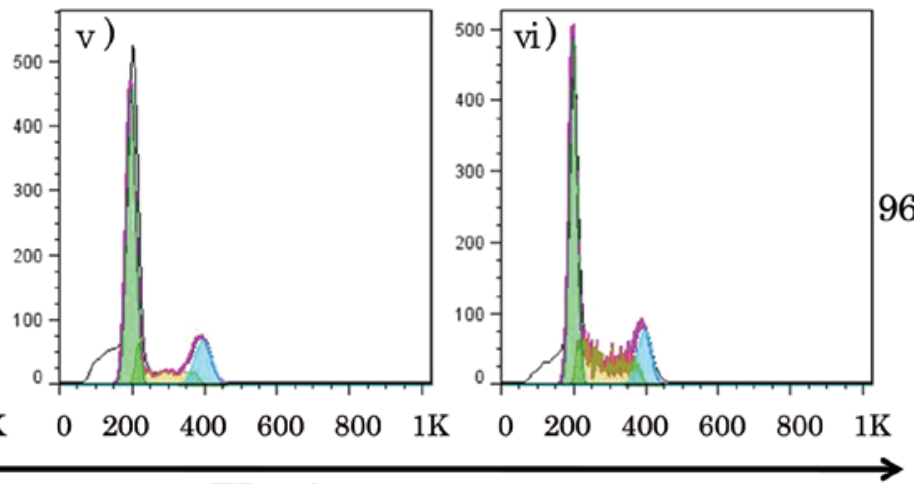

FL2-A

Figure 3. Statin-dependent apoptosis in cholangiocarcinoma cells. Quantitative FACS analysis is shown. (A) Morphological changes were induced by pitavastatin and atorvastatin in YSCCC cells. Forward scatter (FSC) and side scatter (SSC) were reduced after exposure to $20 \mu \mathrm{M}$ pitavastatin (ii) or atorvastatin (iii) for $48 \mathrm{~h}$ compared with DMSO for $48 \mathrm{~h}$ (i), and $20 \mu \mathrm{M}$ pitavastatin (v) or atorvastatin (vi) for $96 \mathrm{~h}$ compared with DMSO for $96 \mathrm{~h}$ (iv). Red and yellow dots indicate a concentration of cells. (B) Propidium iodide staining shows changes in the cell cycle. A marked reduction in the G2M fraction, as well as the appearance of the sub-G1 fraction, was observed upon exposure to $20 \mu \mathrm{M}$ pitavastatin (v) or atorvastatin (vi) for $96 \mathrm{~h}$.

and reduced amounts of apoptosis $(26,27)$. We previously proposed treating cholangiocarcinoma with the HER family tyrosine kinase inhibitor CI-1033 in combination with radiation to target the Fas-FasL pathway (28) and therapy with the 
(A)

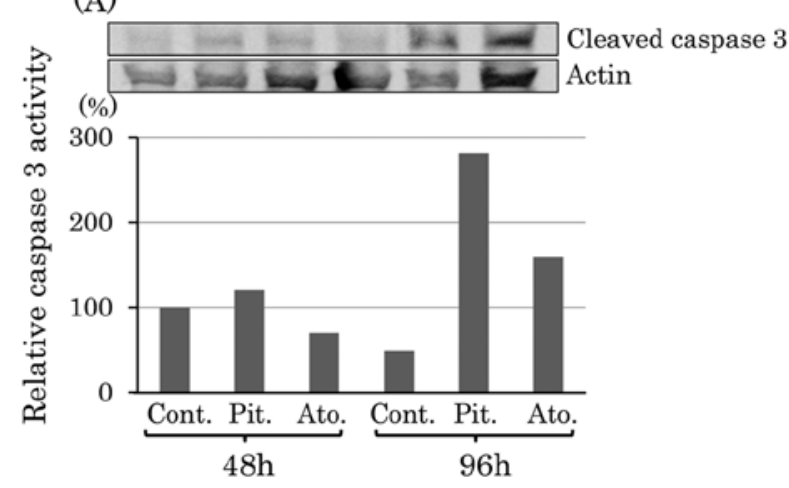

(B)

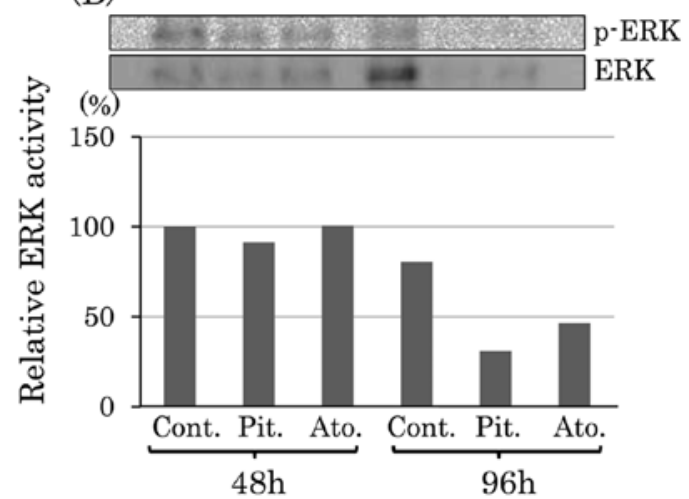

Figure 4. Influence of statins on caspase-3 and ERK in cholangiocarcinoma cells. Changes in caspase-3 and ERK phosphorylation were examined by Western blotting. (A) YSCCC cells exposed to pitavastatin (Pit.) and atorvastatin (Ato.) showed a time-dependent increase in cleaved caspase-3/actin relative to control (Cont.) cells. (B) YSCCC cells exposed to pitavastatin and atorvastatin showed a time-dependent decrease in p-ERK/ERK.

(A) YSCCC
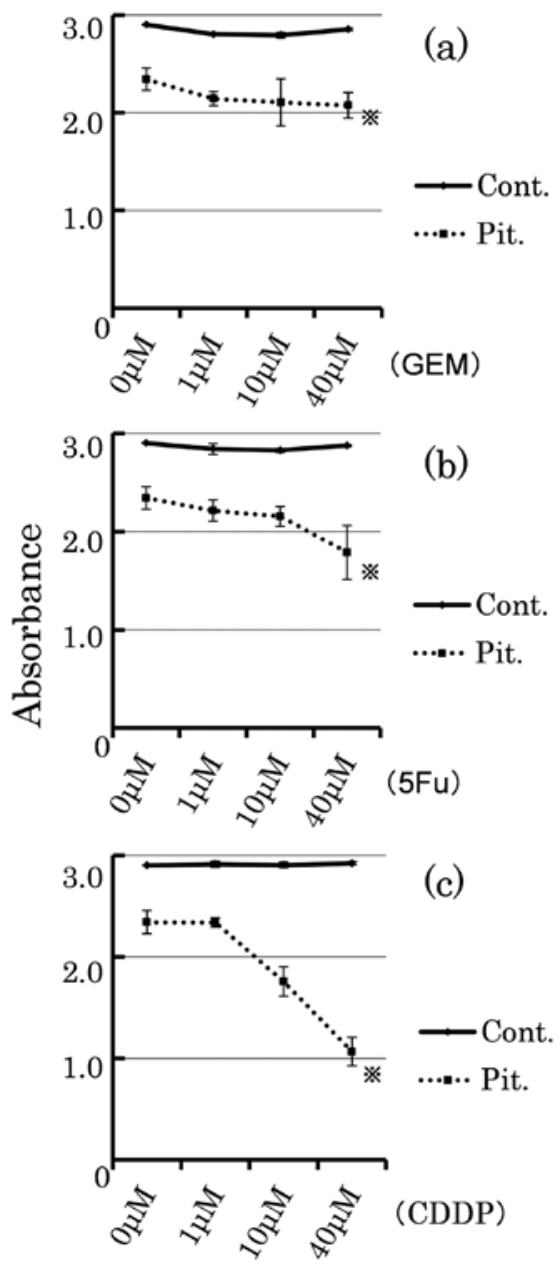

(B) HuCCT1
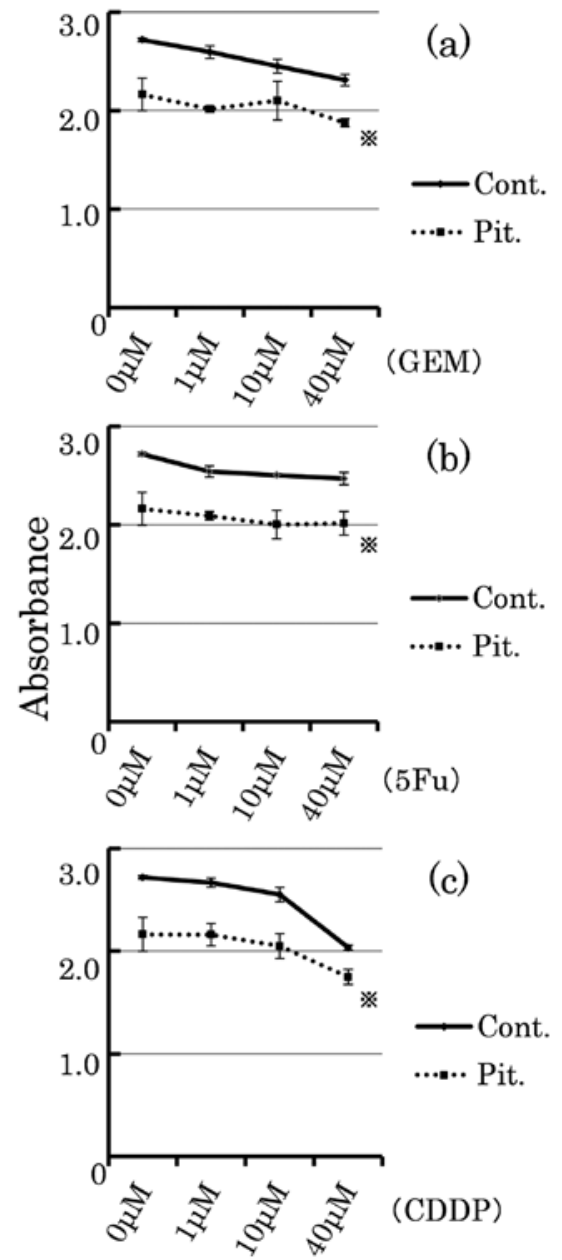

Figure 5. Enhancement of anticancer effect of anticancer drugs by statins in cholangiocarcinoma cells. Compared with anticancer drugs alone, pretreatment with statins enhanced anticancer drug proliferation suppression. The data shown represent the average \pm SD ( $=3$ ) and asterisks indicate a statistical significance compared with the control (Cont.) (t-test, p<0.05). (A) Additive suppression of proliferation by anticancer drugs gemcitabine (a, GEM), 5-FU (b) and cisplatin (c, CDDP) and pitavastatin (Pit.) in YSCCC cells. (B) Additive suppression of proliferation by the anticancer drug gemcitabine (a, GEM), 5-FU (b) and cisplatin (c, CDDP) and pitavastatin (Pit.) in HuCCT1 cells.

EGFR inhibitor ZD-1839 and radiation to target the EGFRRAS-PI3K-AKT pathway (29). However, these reports of combination therapy are not in practical use, prognosis from cholangiocarcinoma remains poor. 
Statins have a variety of effects (30). We demonstrated that two types of hydrophobic statins, pitavastatin and atorvastatin, induced apoptosis in cholangiocarcinoma cells after exposure for as long as 72-96 $\mathrm{h}$ and inhibited proliferation in a dose- and time-dependent manner. In general, there are two types of statins: a) natural or fermented products: lovastatin (Mevacor), simvastatin (Zocor) and pravastatin (Pravachol); and b) synthesized products: fluvastatin (Lecscol), atorvastatin (Lipitor), cerivastatin (Lipobay) and rosuvastatin (Crestor). Pravastatin and cerivastatin are hydrophilic, while simvastatin and lovastatin are hydrophobic $(25,31)$.

By inhibiting HMG-CoA reductase, statins deplete mevalonic acid, a cholesterol precursor, and inhibit cholesterol synthesis. However, multiple aspects of statins beyond their cholesterol-reducing effects have attracted attention and are thought to be dependent on their structural characteristics, such as hydrophilicity and hydrophobicity (25).

Studies on breast, gastrointestinal and prostatic cancer, as well as leukemia and lymphoma, have shown an anticancer effect of statins, but these have yet to be definitively proven. On the other hand, hydrophilic statins have no inhibitory effect on HMG-CoA reductase activity in cells with an extrahepatic origin, while statins are involved in mevalonic acid synthesis and could potentially increase carcinogenic risk (32-34).

Meanwhile, since hydrophobic statins inhibit HMG-CoA reductase activity in cultured human hepatocytes and cells with an extrahepatic origin, the use of hydrophobic statins such as simvastatin and lovastatin should not increase this risk $(33,34)$, and this has been confirmed epidemiologically (35). Therefore, the results of this study showing that the hydrophobic statins pitavastatin and atorvastatin inhibited cholangiocarcinoma cell proliferation are consistent with these previous findings.

On the other hand, sensitivity to statins has been reported to be varied and statin-induced cell cycle arrest and susceptibility to apoptosis differ among breast and prostatic cancer, myeloma, and melanoma cells $(30,36,37)$. Although the cause of these differences is unclear, statins likely do not influence isoprenylation of proteins but rather act on pathways that are affected by different growth characteristics or genetic mutations present in various cancer cells (37).

The reduction in p-ERK/ERK and the elevated caspase-3 levels we detected could indicate that the cells underwent apoptosis that was dependent on the MAPK pathway. Statins were previously reported to enhance the effect of anticancer drugs and radiation therapy in other cancer cells, such as prostatic and pancreatic cancer cells (38-40), and the results of this study demonstrated that statins combined with anticancer drugs such as gemcitabine, cisplatin and 5-FU enhanced their effects in cholangiocarcinoma cells (Fig. 5). Therefore, use of statins has the potential to be a new treatment option for cholangiocarcinoma.

The inclusion of statins in anticancer treatment regimens may reduce the amount of anticancer drugs needed to achieve therapeutic effects, and as such could reduce the side-effects associated with anticancer drugs. Our results could have significant clinical importance since cholangiocarcinoma has a markedly poor prognosis.

In this study, we used two types of cells and two types of statins. Future in vitro and in vivo experiments using different cholangiocarcinoma cells will be necessary to examine the relationship between statin treatment and genetic mutation in cancer cells (37), as well as selection of appropriate statin type, concentration, exposure time, and which anticancer drugs will be most useful for combination therapies. Results from these studies could eventually provide a foundation for future clinical trials.

In conclusion, long exposure to statins inhibited p-ERK and subsequently induced apoptosis in cholangiocarcinoma cells. Moreover, statins were found to have an additive impact on the anticancer effect of pre-existing anticancer drugs in cholangiocarcinoma cells. Statins could thus be a new treatment option for cholangiocarcinoma.

\section{Acknowledgments}

We thank Drs Y. Fujimoto and S. Matsuura, T. Miyamoto, and Ms. Y. Tonouchi, Research Institute for Radiation Biology and Medicine, and Mr. J. Kakimura, Ms. Y. Hayashi, Analysis center of Life Science, Natural Science Center for Basic Research and Development, (Hiroshima University) for useful discussions and technical support, and for the use of their facilities.

\section{References}

1. Rial NS, Henderson JT, Bhattacharyya AK, et al: Use of endoscopic ultrasound for diagnosis of cholangiocarcinoma in auto-immune hepatitis. World J Gastrointestinal Endosc 2: 404-407, 2010.

2. Morise Z, Sugioka A, Tokoro T, et al: Surgery and chemotherapy for intrahepatic cholangiocarcinoma. World J Hepatol 2: 58-64, 2010.

3. Valle J, Wasan H, Palmer DH, et al: Cisplatin plus gemcitabine versus gemcitabine for biliary tract cancer. N Engl J Med 362: $1273-1281,2010$

4. Watanabe Y, Ito T, Shiomi M, et al: Preventive effect of pravastatin sodium, a potent inhibitor of 3-hydroxy-3-methylglutaryl coenzyme A reductase, on coronary atherosclerosis and xanthoma in WHHL rabbits. Biochim Biophys Acta 960: 294-302, 1988.

5. Hoeg JM and Brewer HB Jr: 3-Hydroxy-3-methylglutarylcoenzyme A reductase inhibitors in the treatment of hypercho lesterolemia. JAMA 258: 3532-3536, 1987.

6. Khush KK and Waters DD: Effects of statin therapy on the development and progression of heart failure: mechanisms and clinical trials. J Card Fail 12: 664-674, 2006.

7. Downs JR, Clearfield M, Weis S, et al: Primary prevention of acute coronary events with lovastatin in men and women with average cholesterol levels: results of AFCAPS/TexCAPS. Air Force/Texas Coronary Atherosclerosis Prevention Study. JAMA 279: 1615-1622, 1998.

8. Sacks FM, Pfeffer MA, Moye LA, et al: The effect of pravastatin on coronary events after myocardial infarction in patients with average cholesterol levels. Cholesterol and recurrent events trial investigators. N Engl J Med 335: 1001-1009, 1996.

9. Mason RP, Walter MF and Jacob RF: Effects of HMG-CoA reductase inhibitors on endothelial function: role of microdomains and oxidative stress. Circulation 109: II34-II41, 2004.

10. Hindler K, Cleeland CS, Rivera E and Collard CD: The role of statins in cancer therapy. Oncologist 11: 306-315, 2006.

11. Mo H and Elson CE: Studies of the isoprenoid-mediated inhibition of mevalonate synthesis applied to cancer chemotherapy and chemoprevention. Exp Biol Med 229: 567-585, 2004.

12. Demierre MF, Higgins PD, Gruber SB, Hawk E and Lippman SM: Statins and cancer prevention. Nat Rev Cancer 5: 930-942, 2005.

13. Kozar K, Kaminski R, Legat M, Kopec M, Nowis D, Skierski JS, Koronkiewicz M, Jakobisiak J and Golab J: Cerivastatin demonstrates enhanced antitumor activity against human breast cancer cell lines when used in combination with doxorubicin or cisplatin. Int J Oncol 24: 1149-1157, 2004.

14. Sivaprasad U, Abbas T and Dutta A: Differential efficacy of 3-hydroxy-3-methylglutaryl CoA reductase inhibitors on the cell cycle of prostate cancer cells. Mol Cancer Ther 5: 2310-2316, 2006. 
15. Keyomarsi K, Sandoval L, Band V and Pardee AB: Synchronization of tumour and normal cells from G1 to multiple cell cycles by lovastatin. Cancer Res 51: 3602-3609, 1991.

16. Muck AO, Seeger H and Wallwiener D: Inhibitory effect of statins on the proliferation of human breast cancer cells. Int J Clin Pharmacol Ther 42: 695-700, 2004.

17. Koyuturk M, Ersoz M and Altiok N: Simvastatin induces proliferation inhibition and apoptosis in C6 glioma cells via c-jun N-terminal kinase. Neurosci Lett 370: 212-217, 2004.

18. Campbell MJ, Esserman LJ, Zhou Y, et al: Breast cancer growth prevention by statins. Cancer Res 66: 8707-8714, 2006.

19. Werner M, Sacher J and Hohenegger M: Mutual amplification of apoptosis by statin induced mitochondrial stress and doxorubicin toxicity in human rhabdomyosarcoma cells. Br J Pharm 143 $715-724,2004$

20. Kusama T,Mukai M,Iwasaki T, et al: 3-Hydroxy-3-methylglutarylcoenzyme A reductase inhibitors reduce human pancreatic cancer cell invasion and metastasis. Gastroenterology 122: 308-317, 2002.

21. Paragh G, Kertai P, Kovacs P, Paragh G Jr, Fulop P and Foris G: HMG CoA reductase inhibitor fluvastatin arrests the development of implanted hepatocarcinoma in rats. Anticancer Res 23: 3949-3954, 2003.

22. Poynter JN, Gruber SB, Higgins PD, Almog R, Bonner JD and Rennert HS: Statins and the risk of colorectal cancer. N Engl J Med 352: 2184-2192, 2005.

23. PlatzEA,Leitzmann MF, Visvanathan K, Rimm EB, Stampfer MJ, Willett WC and Giovannucci E: Statin drugs and risk of advanced prostate cancer. J Natl Cancer Inst 98: 1819-1825, 2006.

24. Khurana V, Sheth A, Caldito G and Barkin JS: Statins reduce the risk of pancreatic cancer in humans: a case-control study of half a million veterans. Pancreas 34: 260-265, 2007.

25. Koga T, Shimada Y, Kuroda M, Tsujita Y, Hasegawa K and Yamazaki M: Tissue-selective inhibition of cholesterol synthesis in vivo by pravastatin sodium, a 3-hydroxy-3-methylglutaryl coenzyme A reductase inhibitor. Biochim Biophys Acta 1045: $115-120,1990$.

26. Wise C, Pilanthananond M, Perry BF, et al: Mechanisms of biliary carcinogenesis and growth. World J Gastroenterol 14: 2986-2989, 2008.

27. Duan SG, Long Cheng, et al: The role of MAPK-ERK pathway in 67-kDa laminin receptor-induced FasL expression in human cholangiocarcinoma cells. Dig Dis Sci 55: 2844-2852, 2010.

28. Murakami M, Sasaki T, Yamasaki S, et al: Induction of apoptosis by ionizing radiation and CI-1033 in HuCCT-1 cells. Biochem Biophys Res Comm 319: 114-119, 2004.
29. Miyata H, Sasaki T, Kuwahara K, et al: The effect of ZD1839 (Iressa), a highly selective EGFR tyrosine kinase inhibitor, as a radiosensitiser in bile duct carcinoma cell lines. Int J Oncol 28: 915-921, 2006

30. Minichsdorfer $\mathrm{C}$ and Hohenegger $\mathrm{M}$ : Autocrine amplification loop in statin-induced apoptosis of human melanoma cells. Br J Pharmacol 157: 1278-1290, 2009.

31. Schachter M: Chemical pharmacokinetic and pharmacodynamic properties of statins: an update. Fundam Clin Pharmacol 19: $17-125,2005$.

32. Koyuturk M, Ersoz M and Altiok N: Simvastatin induces apoptosis in human breast cancer cells: P53 and estrogen receptor independent pathway requiring signaling through JNK. Cancer Lett 250: 220-228, 2006.

33. Duncan RE, El-Sohemy A and Archer MC: Mevalonate promotes the growth of tumors derived from human cancer cells in vivo and stimulates proliferation in vitro with enhanced cyclin-dependent kinase-2 activity. J Biol Chem 279: 33079-33084, 2004.

34. Duncan RE, El-Sohemy A and Archer MC: Statins and cancer development. Cancer Epidemiol. Biomarkers Prev 14: 1897-1898, 2005.

35. Pedersen TR, Wilhelmsen L, Faergeman O, Strandberg TE, Thorgeirsson G, Troedsson L, Kristianson J, Berg K, Cook TJ, Haghfelt T, Kjekshus J, Miettinen T, Olsson AG, Pyorala K and Wedel H: Follow-up study of patients randomized in the Scandinavian simvastatin survival study $(4 \mathrm{~S})$ of cholesterol lowering. Am J Cardiol 86: 257-262, 2000.

36. Dimitroulakos J, Ye LY, Benzaquen M, Moore MJ, Kamel-Reid S, Freedman MH, et al: Differential sensitivity of various pediatric cancers and squamous cell carcinomas to lovastatin-induced apoptosis: therapeutic implications. Clin Cancer Res 7: 158-167, 2001.

37. Wong WW, Clendening JW, Martirosyan A, Boutros PC, Bros C, Khosravi $\mathrm{F}$, et al: Determinants of sensitivity to lovastatininduced apoptosis in multiple myeloma. Mol Cancer Ther 6: 1886-1897, 2007.

38. Chan KK, Oza AM and Siu LL: The statins as anticancer agents, Clin Cancer Res 9: 10-19, 2003.

39. Issat T, Nowis D, Legat M, et al: Potentiated antitumor effects of the combination treatment with statins and pamidronate in vitro and in vivo. Int J Oncol 30: 1413-1425, 2007.

40. Mistefa $\mathrm{O}$ and Stenius U: Statins inhibit Akt/PKB signaling via P2X7 receptor in pancreatic cancer cells. Biochem Pharmacol 78: $1115-1126,2009$ 